OPEN ACCESS

Edited by:

Hao Yu,

South China University of

Technology, China

Reviewed by:

Dong Guohui,

Shaanxi University of Science and

Technology, China

Guohong Wang,

Hubei Normal University, China

${ }^{*}$ Correspondence:

Yongqiang Feng

fengyq@sust.edu.cn

Specialty section: This article was submitted to Catalysis and Photocatalysis,

a section of the journal

Frontiers in Chemistry

Received: 15 August 2019 Accepted: 09 October 2019 Published: 24 October 2019

Citation:

Syed N, Huang J, Feng Y, Wang $X$ and Cao L (2019) Carbon-Based

Nanomaterials via Heterojunction Serving as Photocatalyst.

Front. Chem. 7:713

doi: $10.3389 /$ fchem.2019.00713

\section{Carbon-Based Nanomaterials via Heterojunction Serving as Photocatalyst}

\author{
Noureen Syed, Jianfeng Huang, Yongqiang Feng *, Xiao Wang and Liyun Cao \\ Shaanxi Key Laboratory of Green Preparation and Functionalization for Inorganic Materials, Key Laboratory of Auxiliary \\ Chemistry and Technology for Chemical Industry, School of Materials Science and Engineering, Ministry of Education, \\ Shaanxi University of Science and Technology, Xi'an, China
}

Photocatalytic hydrogen production from water splitting is of auspicious possibility to resolve the energy shortage and environmental anxieties. In the past decade, the combination of different carbon-based allotropes with semiconductors of different structure and unique properties to construct heterojunction, which can improve the charge separation, light absorption, and steadiness, offer a promising way to achieve efficient photocatalyst. This review aims to provide an overview of the development for the carbon nanomaterials (CNMs)-based photocatalysts used for hydrogen production from water splitting and photocatalytic degradation of organic pollutants in waste water. The recent progress of CNMs-based heterojunction, including various composite with graphene, fullerene, carbon quantum dots (CQDs), and carbon nanotubes (CNTs) were highlighted. Furthermore, a typical model of CNMs-based Z-scheme heterojunction was also addressed. Finally, a promising perspective on the future development of CNMs-based photocatalysts have been discussed.

Keywords: carbon nanomaterials (CNMs), photocatalysts, heterojunction, water splitting, hydrogen production

\section{INTRODUCTION}

Photocatalysts facing toward energy crisis and environmental issues have attracted increased intention as one of the best way for the reduction of toxic contaminants and $\mathrm{H}_{2}$ production (Hisatomi et al., 2014; Low et al., 2015; Dai et al., 2017; Liu G. et al., 2019). However, challenges for the photocatalysts remains regarding to the limited light absorption, high charge recombination, and low quantum yield (Sudhaik et al., 2018). Up to now various photocatalysts have been developed to resolve these issues, among which carbon-based photocatalysts recently aroused tremendous interest due to their large surface area, favorable electronic conductivity, low fabrication cost, and high chemical/thermal stability (Yang et al., 2014; Xia et al., 2017; Ma et al., 2018). These unique properties make carbon nanomaterials (CNMs) as the most promising candidate for photocatalysts (Yu et al., 2014).

The most widely used CNMs for the synthesis of photocatalysts, such as graphene (Yu et al., 2016), carbon nanotubes (CNTs) (Zhang Y. et al., 2019), carbon quantum dots (CQDs) (Li Y. et al., 2018), fullerene (Song et al., 2017), and graphitic carbon nitride $\left(g-C_{3} N_{4}\right)$ (Zhang S. et al., 2019) have attracted great attention due to their high physiochemical stability, earth abundant, and low synthesis cost. Moreover, the electronic structure and photocatalytic properties of CNMs could be adjusted through morphology and interfacial modulation (Xin et al., 2018). Whereas, pristine CNMs suffer from rapid recombination of electron-hole pair and narrow visible light adsorption. 
One of the best strategy to solve this problem is to construct heterojunction via assembly of CNMs with semiconductors. Especially, the modified CNMs-based Z-scheme heterojunction, resembling the natural photosynthetic model, benefit from various merits including improved light harvesting, spatially separated electron and hole sites and strong redox ability (Tong et al., 2012). Beside the structure modification of the Z-scheme heterojunction, the introduced CNMs also serve as electron mediator between two semiconductors, which actually reduce the resistance and improve the charge separation and stability.

This paper aims to provide an overview of carbonbased photocatalysts in water splitting for $\mathrm{H}_{2}$ production as well as degradation of organic pollutants. The properties, performances, and combinations of different allotropes of carbon as photocatalysts were discussed. Photocatalytic enhancements by solid Z-scheme heterojunction were also reviewed.

\section{CARBON-BASED PHOTOCATALYSTS}

\section{Graphene as Photocatalyst}

Graphene with excellent physical and chemical properties discovered in 2004, holding $\mathrm{sp}^{2}$-hybridized atoms tightly assembled into an ordered two-dimensional (2D) honeycomb construct, offer new opportunities in designing efficient photocatalytic materials with high stability (Gupta et al., 2019; Madkour, 2019). Recent demand for the synthesis of metalfree photocatalysts is on the verge of increase. Gong et al. successfully obtained graphene/g- $\mathrm{C}_{3} \mathrm{~N}_{4}$ nanocomposites by impregnation chemical reduction strategy, which served as active photocatalysts for $\mathrm{H}_{2}$ production in visible light (Gong et al., 2018). Moreover, 2D graphene and transition metal dichalcogenides (TMDCs), have become versatile nanomaterials for the fast progress of photocatalysts due to their unique properties in optical, electrical, thermal, and mechanical aspects (Rosman et al., 2018). One of the works done by Lv et al. that elaborated graphene composite without noble metal, revealed that graphene attached to semiconductor surface fabricated by hydrothermal method can efficiently accommodate and transport electrons from the excited semiconductor, which not only hindered charge recombination but also improved charge transfer, giving rise to high photocatalytic efficiency ( $\mathrm{Lv}$ et al., 2012). This work confirmed the significant contribution of graphene in enhancing the photocatalytic activity. Afterwards, many graphene-based photocatalysts have been developed. For example, Quiroz-Cardoso et al. (2019) recently reported graphene in combination with nickel nanoparticles modified CdS fibers (Ni/GO-CdS) enhanced the photocatalytic hydrogen production, which was 6.3 times higher than that of bare CdS. Considering the superior conductivity and tunable structure, graphene would be the most promising candidate for photocatalysts. Design and construction of novel hierarchical architectures hybridizing with graphene nanostructures would provide plenty of rooms for photocatalytic application.

\section{CNTs as Photocatalyst}

Photocatalytic water-splitting technology based on CNTsmodified nanomaterials has exhibited great potential for hydrogen production in view of their low cost and high stability
(Yi et al., 2018). For example, Zheng et al. (2008) has offered new opportunities for achieving high photocatalytic activity with high stability. In combination of CNTs with graphene not only increase reaction sites but also inhibit the recombination of photo-excited electron-hole pairs (Bhanvase et al., 2017). In addition, CNTs-based photocatalysts also revealed high activity on the photocatalytic degradation of organic pollutants due to $\pi$-system or formation of heterojunction. For example, CNT-modified hierarchical microspheres $\mathrm{ZnO}$ enhanced the visible light adsorption and charge separation process, exhibiting excellent photocatalytic performance much better than the pure $\mathrm{ZnO}$ for the reduction of the organic molecules in the industrial effluents (Ahmad et al., 2014). Combination of CNT with other photocatalysts could enhance the conductivity and facilitate the charge transfer process during the photocatalytic reaction. To further improve the performance in future, more efforts should be made to in-situ synthesize CNT-based composite in order to strengthen the synergetic interaction between CNT and other nanostructures.

\section{CQDs as Photocatalyst}

CQDs as an emerging and recently developed CNMs provided well-controlled intrinsic characteristics because of its unique optical and electrical properties, as well as the special fluorescence emission feature (Zhang et al., 2017). Since their discovery in 2004 (Xu et al., 2004), CQDs have been utilized in various application, including chemical sensor, bioimaging, nanomedicine, photocatalysts, etc. Particularly, in photocatalytic application, CQDs showed the most promising potential for photocatalytic $\mathrm{H}_{2}$ production. Moreover, CQDs can act both as electron acceptor and donor leading to effective electron and hole separation, and extensively modify the photo-absorption range of semiconductor materials with large band gap to visible regions (Pirsaheb et al., 2018). Wang et al. demonstrated that metaldoped CQDs combined with CdS nanowires as a co-catalyst showed much better hydrogen production performance than the undoped CQDs/CdS composite (Wang Y. et al., 2019). One more example examined by Wang et al. demonstrated that the visible-light-sensitive $\mathrm{BiVO}_{4}$ quantum tube $\left(\mathrm{q}-\mathrm{BiVO}_{4}\right)$ decorated with CQDs displayed outstanding photocatalytic performance, whose kinetic constants for the degradation of phenol and rhodamine $\mathrm{B}(\mathrm{RhB})$ were 3.0 and 2.4 times higher than those of the sole q- $\mathrm{BiVO}_{4}$, respectively (Wang G. et al., 2019). Due to the potential both as electron donor and acceptor, CQD should be further investigated in the field of photocatalytic application. Developing novel and facile green synthesis method to fabricate CQD-based CNMs, especially the metal-free catalysts deserves more attention.

\section{Fullerene as Photocatalyst}

Fullerene $\left(\mathrm{C}_{60}\right)$ with a close-shell shape consisting of 20 hexagons and 12 pentagons, holding 30 orbital bonding with 60 p-electrons, has been recognized as the most significant carbon allotropes because of the unique chemical and physical characteristics (Lindqvist et al., 2014). Besides, $\mathrm{C}_{60}$ is both an excellent electron acceptor and donor, which facilitate the functionality of fullerene-based carbon materials in photocatalytic applications. Encapsulation of fullerene into 
CNTs is super effective technique, pioneered by Smith et al. (1998), to fabricate heterojunction with unique electronic characteristics (Rahimi-Nasrabadi et al., 2017). Song et al. synthesized a novel $\mathrm{C}_{60}$ /graphene/g- $\mathrm{C}_{3} \mathrm{~N}_{4}$ composite with high hydrogen production efficiency for water splitting (Song et al., 2017). The synergetic effect between graphene and $C_{60}$ improved the transportation and utilization efficiency of photo-generated electrons and accelerated the separation of photo-generated electron and hole pairs, thus considerably enhancing the hydrogen generation ability of $g-\mathrm{C}_{3} \mathrm{~N}_{4}$. Fullerene and its derivatives have been widely used in the organic photovoltaic device, however, their application in photocatalysis for hydrogen production and organic pollutants degradation is in the infancy. Until now, most works only focused on the $\mathrm{C}_{60}$, other members in fullerene family such as $\mathrm{C}_{70}$ and their derivatives should be pay more attention for photocatalysts in future.

\section{g- $\mathrm{C}_{3} \mathrm{~N}_{\mathbf{4}}$ as Photocatalyst}

Recently, the improvement of photocatalytic activity by using g- $\mathrm{C}_{3} \mathrm{~N}_{4}$ has turned into a hot research subject because of its tunable electronic band structure, highly stable physiochemical properties, simple manufacturing and low cost (Dong et al., 2016, 2019; Li Y. et al., 2018). Wang J. et al. (2019) fabricated a $3 \mathrm{D}$ flower-like $\mathrm{TiO}_{2}$ hybridized with $2 \mathrm{D}$ g- $\mathrm{C}_{3} \mathrm{~N}_{4}$ nanosheet through a hydrothermal and calcination process. The resulting $\mathrm{TiO}_{2} / \mathrm{g}-\mathrm{C}_{3} \mathrm{~N}_{4}$ composite exhibited a much enhanced efficiency of photocatalytic hydrogen production, which is 7.7 and 1.9 times higher than that of the pure $\mathrm{g}-\mathrm{C}_{3} \mathrm{~N}_{4}$ and $\mathrm{TiO}_{2}$, respectively. It was reported that the extended visible light adsorption by g- $\mathrm{C}_{3} \mathrm{~N}_{4}$ make a contribution to the improved photocatalytic performance. In addition, the activity of $\mathrm{g}-\mathrm{C}_{3} \mathrm{~N}_{4}$ could also be improved by doping. Zhou et al. (2019) reported that the $\mathrm{NO}$ removal rate of $\mathrm{g}-\mathrm{C}_{3} \mathrm{~N}_{4}$ could be enhanced by 1.5 times after Sr doping. Density functional theory (DFT) method is powerful for systematically depicting the electronic structures and understanding energy-related mechanism for photocatalytic reaction. The results revealed that different doping modes of $\mathrm{Sr}$ including intercalation, cavity padding, replacement of triazine $\mathrm{N}$ and bridging $\mathrm{N}$ could decrease the band gap of $\mathrm{g}-\mathrm{C}_{3} \mathrm{~N}_{4}$, thus facilitating the charge transfer process.

\section{HETEROJUNCTION}

Many efforts have been made to realize the complete utilization of photo-excited charge carriers and inhibit recombination of electron-hole pairs during the photocatalytic process, among

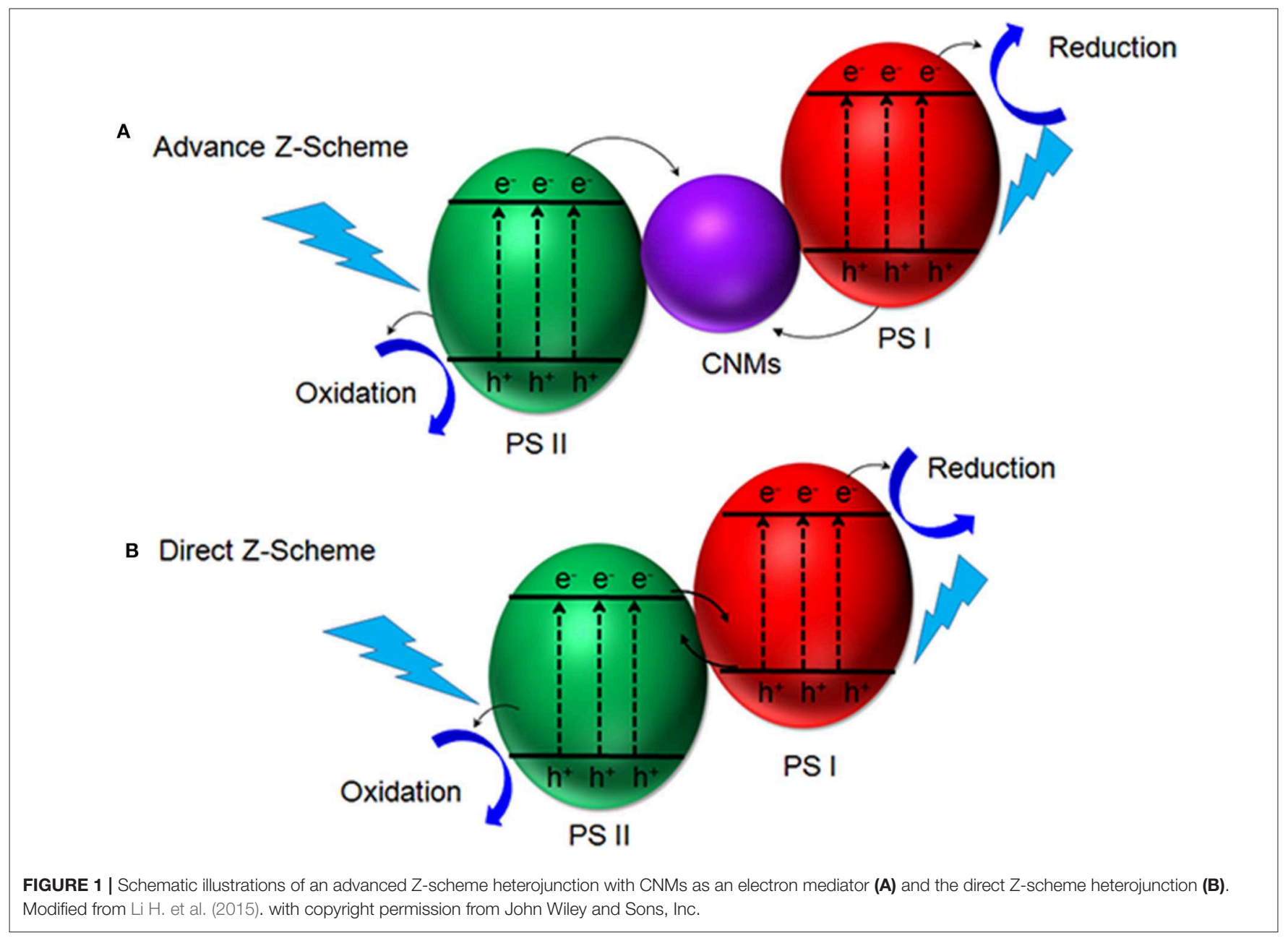


which fabrication of heterojunction is one of the best approach to improve the charge separation efficiency and reduce the recombination of the photogenerated electron-hole pairs (Moniz et al., 2015; Wang et al., 2018). The most commonly-investigated heterojunction is constructed via two solid semiconductors and one electron mediator as illustrated in Figure 1, forming an advanced solid-type Z-scheme configuration. The main mechanism for Z-scheme heterojunction is inspired by the natural photosynthesis process. Electrons of photocatalysts I are recombined with holes in photocatalysts II via electron mediator under light, which inhibits the recombination of photo-induced charge carrier and stay their redox property (Bard and Fox, 1995).

In order to improve the conductivity of semiconductor photocatalysts, CNMs like graphene, fullerene, CNTs and their derivatives have been widely used in different heterojunction as an electron mediator to increase the conductivity (Natarajan et al., 2018). Table 1 summarize several typical carbonbased photocatalysts. As compared with other carbon-based heterojunction photocatalysts, graphene exhibits a plenty of merits such as low cost, large surface area and tunable band structure (Li X. et al., 2018). Gebreslassie et al. demonstrated that graphene as an electron mediator can significantly enhance the photocatalytic activity, which showed 7-15-folds higher $\mathrm{H}_{2}$ production compared with their pristine compounds without the aid of graphene (Gebreslassie et al., 2019). Similarly, Jiang et al. synthesized a solid-state Z-scheme $\mathrm{Bi}_{2} \mathrm{WO}_{6} / \mathrm{CNTs} / g-\mathrm{C}_{3} \mathrm{~N}_{4}$ composite, where CNT acted as an electron mediator (Jiang et al., 2018). This composite disclosed an outperforming photocatalytic activity than the pure $\mathrm{Bi}_{2} \mathrm{WO}_{6}$ and $g-\mathrm{C}_{3} \mathrm{~N}_{4}$ for the degradation of 2,4-dibromophenol. Recently, CQDs have also been used as electron mediator to build solidstate Z-scheme heterojunction. In 2019, Liu et al. fabricated a CQD-based Z-scheme heterojunction by bridging $\mathrm{TiO}_{2}$ and $\mathrm{Cd}_{0.5} \mathrm{Zn}_{0.5} \mathrm{~S}$ with CQDs, which exhibits super photocatalytic activity for $\mathrm{H}_{2}$ evolution (Liu E. et al., 2019). Meanwhile, Pan et al. constructed a sandwich-type structure, where CQDs were embedded between $\mathrm{CdS}$ and $\mathrm{BiOCl}$ (Pan et al., 2018). The resulting CdS/CQDs/BiOCl heterojunction displayed much higher photocatalytic activity on the degradation of $\mathrm{RhB}$ and phenol under visible and UV light illumination compared with $\mathrm{BiOCl}, \mathrm{CdS} / \mathrm{BiOCl}$, and CQDs/BiOCl.

\section{CONCLUSIONS AND PERSPECTIVES}

Carbon-based nanomaterials with low cost and favorable catalytic performance have been extensively used for photocatalytic reactions in the fields of energy conversion and environmental protection. In this review, CNMs such as graphene, CNTs, CQDs, $\mathrm{C}_{60}$, and $\mathrm{g}-\mathrm{C}_{3} \mathrm{~N}_{4}$, etc. used as photocatalysts in the application for $\mathrm{H}_{2}$ production from water splitting and photocatalytic degradation of organic pollutants in waste water were comprehensively overviewed.

TABLE 1 | Summary of carbon-based photocatalysts.

\begin{tabular}{|c|c|c|c|}
\hline Photocatalysts & Heterojunction type & Synthesis method & References \\
\hline PPTA/MWNTs & N.A. ${ }^{a}$ & Polycondensation & Mazrouaa et al., 2019 \\
\hline $\mathrm{g}-\mathrm{C}_{3} \mathrm{~N}_{4}$ /graphene/ $\mathrm{NiFe}_{2} \mathrm{O}_{4}$ & Solid state Z-scheme & Hydrothermal & Gebreslassie et al., 2019 \\
\hline CN/CNT/BWO & Solid state Z-scheme & N.A. & Jiang et al., 2018 \\
\hline $\mathrm{Bi}_{2} \mathrm{WO}_{6} / \mathrm{g}-\mathrm{C}_{3} \mathrm{~N}_{4}$ & Direct Z-scheme & Hydrothermal & Li M. et al., 2015 \\
\hline $\mathrm{ZnO} / \mathrm{g}-\mathrm{C}_{3} \mathrm{~N}_{4}$ & Direct Z-scheme & Solid state & Yu et al., 2015 \\
\hline $\mathrm{Cd}_{0.5} \mathrm{Zn}_{0.5} \mathrm{~S} / \mathrm{CQD} / \mathrm{TiO}_{2}$ & Solid state Z-scheme & Hydrothermal & Liu E. et al., 2019 \\
\hline Cds/CQDs/BiOCl & Solid state Z-scheme & Facile-region & Pan et al., 2018 \\
\hline $\mathrm{Ru} / \mathrm{SrTiO}_{3}$ & Z-scheme & Hummers method & Iwase et al., 2011 \\
\hline $\mathrm{SnS}_{2} / \mathrm{g}-\mathrm{C}_{3} \mathrm{~N}_{4}$ & Z-scheme & Hydrothermal & Di et al., 2017 \\
\hline $\mathrm{SnO}_{2-x} / g-\mathrm{C}_{3} \mathrm{~N}_{4}$ & Z-scheme & Solid-state synthesis & He et al., 2015 \\
\hline $\mathrm{CdS} / \mathrm{SiC}$ & Z-scheme & Hydrothermal & Peng et al., 2015 \\
\hline CdS/graphene & N.A. & N.A. & Li et al., 2011 \\
\hline $\mathrm{Znln}_{2} \mathrm{~S}_{4} / \mathrm{RGO}$ & N.A. & Solvothermal & Ye et al., 2014 \\
\hline $\mathrm{Bi}_{2} \mathrm{WO}_{6} /$ graphene & N.A. & Sonochemical & Sun et al., 2014 \\
\hline Graphene/g- $\mathrm{C}_{3} \mathrm{~N}_{4}$ & N.A. & Impregnation-chemical reduction & Xiang et al., 2011 \\
\hline Nanoparticle/graphene & N.A. & One-pot solution & Lv et al., 2012 \\
\hline $\mathrm{TiO}_{2} /$ graphene & N.A. & Sol gel method & Zhang et al., 2010 \\
\hline $\mathrm{TiO}_{2} /$ carbon dots & N.A. & Hydrothermal & Wang et al., 2014 \\
\hline CdS/graphene & N.A. & Hydrothermal & Ye et al., 2012 \\
\hline $\mathrm{Ta}_{2} \mathrm{O}_{5} / \mathrm{CNT}$ & Schottky heterojunction & N.A. & Cherevan et al., 2014 \\
\hline $\mathrm{Ni} / \mathrm{GO}-\mathrm{CdS}$ & N.A. & Photo-deposition & Quiroz-Cardoso et al., 2019 \\
\hline La-CNTs/TiO 2 & N.A. & Sol-gel method & Tahir, 2019 \\
\hline $\mathrm{TiO}_{2} / \mathrm{CQD}$ & N.A. & Green synthesis & Sargin et al., 2019 \\
\hline
\end{tabular}

${ }^{a}$ N.A., Not Available. 
It could be concluded that CNMs exhibit intriguing property in enhancing the photocatalytic performance of various photocatalysts. With the rapid development of advanced technique, various carbon-based Z-scheme heterojunction with excellent photocatalytic performance have been established. This type of heterojunction inspired by artificial photosynthesis method possess many advantages including increased light harvesting and favorable strong redox capability, which highly improved the photocatalytic performance compared with the direct heterojunction. Different type of carbon allotropes are the good performer as an electron mediator in solid-state Z-scheme heterojunction while the selection of proper electron mediator with specific composite to different materials according to their specific function is challenging and crucial. Obviously photocatalytic efficiency depends on the type of material. The development of novel photocatalysts with better catalytic performance has always been put forward to the frontiers of nanomaterials and a further understanding of heterojunction mechanisms are also of great importance to promote the application of photocatalysts.

\section{REFERENCES}

Ahmad, M., Ahmed, E., Hong, Z. L., Ahmed, W., Elhissi, A., and Khalid, N. R. (2014). Photocatalytic, sonocatalytic and sonophotocatalytic degradation of Rhodamine B using $\mathrm{ZnO} / \mathrm{CNTs}$ composites photocatalysts. Ultrason. Sonochem. 21, 761-773. doi: 10.1016/j.ultsonch.2013.08.014

Bard, A. J., and Fox, M. A. (1995). Artificial photosynthesis: solar splitting of water to hydrogen and oxygen. Acc. Chem. Res. 28, 141-145. doi: 10.1021/ar00051a007

Bhanvase, B. A., Shende, T. P., and Sonawane, S. H. (2017). A review on graphene- $\mathrm{TiO}_{2}$ and doped graphene- $\mathrm{TiO}_{2}$ nanocomposite photocatalyst for water and wastewater treatment. Environ. Tech. Rev. 6, 1-14. doi: 10.1080/21622515.2016.1264489

Cherevan, A. S., Gebhardt, P., Shearer, C. J., Matsukawa, M., Domen, K., and Eder, D. (2014). Interface engineering in nanocarbon- $\mathrm{Ta}_{2} \mathrm{O}_{5}$ hybrid photocatalysts. Energ. Environ. Sci. 7, 791-796. doi: 10.1039/C3EE42558D

Dai, D., Xu, H., Ge, L., Han, C., Gao, Y., Li, S., et al. (2017). In-situ synthesis of CoP co-catalyst decorated $\mathrm{Zn}_{0.5} \mathrm{Cd}_{0.5} \mathrm{~S}$ photocatalysts with enhanced photocatalytic hydrogen production activity under visible light irradiation. Appl. Catal. B Environ. 217, 429-436. doi: 10.1016/j.apcatb.2017.06.014

Di, T., Zhu, B., Cheng, B., Yu, J., and Xu, J. (2017). A direct Z-scheme g-C $\mathrm{C}_{4} / \mathrm{SnS}_{2}$ photocatalyst with superior visible-light $\mathrm{CO}_{2}$ reduction performance. J. Catal. 352, 532-541. doi: 10.1016/j.jcat.2017.06.006

Dong, G., Yang, L., Wang, F., Zang, L., and Wang, C. (2016). Removal of nitric oxide through visible light photocatalysis by $\mathrm{g}-\mathrm{C}_{3} \mathrm{~N}_{4}$ modified with perylene imides. ACS Catal. 6, 6511-6519. doi: 10.1021/acscatal.6b01657

Dong, G., Zhao, L., Wu, X., Zhu, M., and Wang, F. (2019). Photocatalysis removing of NO based on modified carbon nitride: the effect of celestite mineral particles. Appl. Catal. B Environ. 245, 459-468. doi: 10.1016/j.apcatb.2019. 01.013

Gebreslassie, G., Bharali, P., Chandra, U., Sergawie, A., Boruah, P. K., Das, M. R., et al. (2019). Novel g- $\mathrm{C}_{3} \mathrm{~N}_{4} /$ graphene/ $\mathrm{NiFe}_{2} \mathrm{O}_{4}$ nanocomposites as magnetically separable visible light driven photocatalysts. J. Photoch. Photobio. A 382:111960. doi: 10.1016/j.jphotochem.2019.111960

Gong, S., Jiang, Z., Zhu, S., Fan, J., Xu, Q., and Min, Y. (2018). The synthesis of graphene- $\mathrm{TiO}_{2} / \mathrm{g}-\mathrm{C}_{3} \mathrm{~N}_{4}$ super-thin heterojunctions with enhanced visible-light photocatalytic activities. J. Nanopart. Res. 20:310. doi: 10.1007/s11051-018-4399-8

Gupta, N., Rai, D. B., Jangid, A. K., and Kulhari, H. (2019). A review of theranostics applications and toxicities of carbon nanomaterials. Curr. Drug Metab. 20, 506-532. doi: 10.2174/1389200219666180925094515

\section{AUTHOR CONTRIBUTIONS}

NS and YF organized and wrote the manuscript. XW, JH, and LC discussed the results and revised the paper. All authors approved this publication.

\section{FUNDING}

This work was financially supported by the National Natural Science Foundation of China (21603243), Beijing National Laboratory for Molecular Sciences (BNLMS201805), Natural Science Foundation of Shaanxi Province (2019JQ-203), Key Laboratory of Auxiliary Chemistry and Technology for Chemical Industry (KFKT2019-06), and Natural Science Foundation of Shaanxi Provincial Department of Education (17JK0093). YF was grateful for the support from the 1000 Youth Talents Plan of Shaanxi Province, Platform Construction Fund for Imported Talent of Shaanxi University of Science and Technology (134080038) and Youth Talents of Shaanxi University of Science and Technology (2016QNBJ-14).

He, Y., Zhang, L., Fan, M., Wang, X., Walbridge, M. L., Nong, Q., et al. (2015). Z-scheme $\mathrm{SnO}_{2}-\mathrm{x} / \mathrm{g}-\mathrm{C}_{3} \mathrm{~N}_{4}$ composite as an efficient photocatalyst for dye degradation and photocatalytic $\mathrm{CO}_{2}$ reduction. Sol. Energ. Mater. Sol. C. 137, 175-184. doi: 10.1016/j.solmat.2015.01.037

Hisatomi, T., Kubota, J., and Domen, K. (2014). Recent advances in semiconductors for photocatalytic and photoelectrochemical water splitting. Chem. Soc. Rev. 43, 7520-7535. doi: 10.1039/C3CS60378D

Iwase, A., Ng, Y. H., Ishiguro, Y., Kudo, A., and Amal, R. (2011). Reduced graphene oxide as a solid-state electron mediator in z-scheme photocatalytic water splitting under visible light. J. Am. Chem. Soc. 133, 11054-11057. doi: 10.1021/ja203296z

Jiang, D., Ma, W., Xiao, P., Shao, L., Li, D., and Chen, M. (2018). Enhanced photocatalytic activity of graphitic carbon nitride/carbon nanotube $/ \mathrm{Bi}_{2} \mathrm{WO}_{6}$ ternary $\mathrm{Z}$-scheme heterojunction with carbon nanotube as efficient electron mediator. J. Colloid Interf. Sci. 512, 693-700. doi: 10.1016/j.jcis.2017.10.074

Li, H., Zhou, Y., Tu, W., Ye, J., and Zou, Z. (2015). State-of-the-art progress in diverse heterostructured photocatalysts toward promoting photocatalytic performance. Adv. Fun. Mater. 25, 998-1013. doi: 10.1002/adfm.201401636

Li, M., Zhang, L., Fan, X., Zhou, Y., Wu, M., and Shi, J. (2015). Highly selective $\mathrm{CO}_{2}$ photoreduction to $\mathrm{CO}$ over g- $\mathrm{C}_{3} \mathrm{~N}_{4} / \mathrm{Bi}_{2} \mathrm{WO}_{6}$ composites under visible light. J. Mater. Chem. A 3, 5189-5196. doi: 10.1039/C4TA06295G

Li, Q., Guo, B., Yu, J., Ran, J., Zhang, B., Yan, H., et al. (2011). Highly efficient visible-light-driven photocatalytic hydrogen production of CdScluster-decorated graphene nanosheets. J. Am. Chem. Soc. 133, 10878-10884. doi: 10.1021/ja2025454

Li, X., Shen, R., Ma, S., Chen, X., and Xie, J. (2018). Graphene-based heterojunction photocatalysts. Appl. Surf. Sci. 430, 53-107. doi: 10.1016/j.apsusc.2017.08.194

Li, Y., Feng, X., Lu, Z., Yin, H., Liu, F., and Xiang, Q. (2018). Enhanced photocatalytic $\mathrm{H}_{2}$-production activity of C-dots modified g$\mathrm{C}_{3} \mathrm{~N}_{4} / \mathrm{TiO}_{2}$ nanosheets composites. J. Colloid Interf. Sci. 513, 866-876. doi: 10.1016/j.jcis.2017.12.002

Lindqvist, C., Bergqvist, J., Feng, C.-C., Gustafsson, S., Bäcke, O., Treat, N. D., et al. (2014). Fullerene nucleating agents: a route towards thermally stable photovoltaic blends. Adv. Energ. Mater. 4:1301437. doi: 10.1002/aenm.201301437

Liu, E., Xu, C., Jin, C., Fan, J., and Hu, X. (2019). Carbon quantum dots bridged $\mathrm{TiO}_{2}$ and $\mathrm{Cd}_{0.5} \mathrm{Zn}_{0.5} \mathrm{~S}$ film as solid-state $\mathrm{Z}$-scheme photocatalyst with enhanced $\mathrm{H}_{2}$ evolution activity. J. Taiwan Inst. Chem. Eng. 97, 316-325. doi: 10.1016/j.jtice.2019.02.027

Liu, G., Wang, G., Hu, Z., Su, Y., and Zhao, L. (2019). $\mathrm{Ag}_{2} \mathrm{O}$ nanoparticles decorated $\mathrm{TiO}_{2}$ nanofibers as a pn heterojunction for enhanced photocatalytic 
decomposition of RhB under visible light irradiation. Appl. Surf. Sci. 465, 902-910. doi: 10.1016/j.apsusc.2018.09.216

Low, J., Yu, J., and Ho, W. (2015). Graphene-based photocatalysts for $\mathrm{CO}_{2}$ reduction to solar fuel. J. Phys. Chem. Lett. 6, 4244-4251. doi: 10.1021 /acs.jpclett.5b01610

Lv, X.-J., Fu, W.-F., Chang, H.-X., Zhang, H., Cheng, J.-S., Zhang, G.J., et al. (2012). Hydrogen evolution from water using semiconductor nanoparticle/graphene composite photocatalysts without noble metals. J. Mater. Chem. 22, 1539-1546. doi: 10.1039/C1JM14502A

Ma, X., Xiang, Q., Liao, Y., Wen, T., and Zhang, H. (2018). Visiblelight-driven CdSe quantum dots/graphene/ $\mathrm{TiO}_{2}$ nanosheets composite with excellent photocatalytic activity for $E$. coli disinfection and organic pollutant degradation. Appl. Surf. Sci. 457, 846-855. doi: 10.1016/j.apsusc.2018.07.003

Madkour, L. H. (2019). Carbon Nanomaterials and Two-Dimensional Transition Metal Dichalcogenides (2D TMDCs). Nanoelectronic Materials: Fundamentals and Applications. Cham: Springer, 165-245.

Mazrouaa, A. M., Mansour, N. A., Abed, M. Y., Youssif, M. A., Shenashen, M. A., and Awual, M. R. (2019). Nano-composite multi-wall carbon nanotubes using poly(p-phenylene terephthalamide) for enhanced electric conductivity. J. Environ. Chem. Eng. 7:103002. doi: 10.1016/j.jece.2019.1 03002

Moniz, S. J. A., Shevlin, S. A., Martin, D. J., Guo, Z.-X., and Tang, J. (2015). Visiblelight driven heterojunction photocatalysts for water splitting - a critical review. Energ. Environ. Sci. 8, 731-759. doi: 10.1039/C4EE03271C

Natarajan, T. S., Thampi, K. R., and Tayade, R. J. (2018). Visible light driven redox-mediator-free dual semiconductor photocatalytic systems for pollutant degradation and the ambiguity in applying Z-scheme concept. Appl. Catal. B Environ. 227, 296-311. doi: 10.1016/j.apcatb.2018.01.015

Pan, J., Liu, J., Zuo, S., Khan, U. A., Yu, Y., and Li, B. (2018). Structure of Z-scheme CdS/CQDs/BiOCl heterojunction with enhanced photocatalytic activity for environmental pollutant elimination. Appl. Surf. Sci. 444, 177-186. doi: 10.1016/j.apsusc.2018.01.189

Peng, Y., Guo, Z., Wang, D., Pan, N., and Yuan, W. (2015). Heterogeneous nucleation of CdS to enhance visible-light photocatalytic hydrogen evolution of SiC/CdS composite. Appl. Phys. Lett. 107:012102. doi: 10.1063/1.49 23399

Pirsaheb, M., Asadi, A., Sillanpää, M., and Farhadian, N. (2018). Application of carbon quantum dots to increase the activity of conventional photocatalysts: A systematic review. J. Mol. Liq. 271, 857-871. doi: 10.1016/j.molliq.2018.09.064

Quiroz-Cardoso, O., Oros-Ruiz, S., Solís-Gómez, A., López, R., and Gómez, R. (2019). Enhanced photocatalytic hydrogen production by CdS nanofibers modified with graphene oxide and nickel nanoparticles under visible light. Fuel 237, 227-235. doi: 10.1016/j.fuel.2018.10.013

Rahimi-Nasrabadi, M., Khoshroo, A., and Mazloum-Ardakani, M. (2017). Electrochemical determination of diazepam in real samples based on fullerene-functionalized carbon nanotubes/ionic liquid nanocomposite. Sensors Actuat $B$ Chem 240, 125-131. doi: 10.1016/j.snb.2016. 08.144

Rosman, N. N., Mohamad Yunus, R., Jeffery Minggu, L., Arifin, K., Salehmin, M. N. I., Mohamed, M. A., et al. (2018). Photocatalytic properties of twodimensional graphene and layered transition-metal dichalcogenides based photocatalyst for photoelectrochemical hydrogen generation: An overview. Int. J. Hydrogen Energ. 43, 18925-18945. doi: 10.1016/j.ijhydene.2018. 08.126

Sargin, I., Yanalak, G., Arslan, G., and Patir, I. H. (2019). Green synthesized carbon quantum dots as $\mathrm{TiO}_{2}$ sensitizers for photocatalytic hydrogen evolution. Int. J. Hydrogen Energ. 44, 21781-21789. doi: 10.1016/j.ijhydene.2019.06.168

Smith, B. W., Monthioux, M., and Luzzi, D. E. (1998). Encapsulated $\mathrm{C}_{60}$ in carbon nanotubes. Nature 396, 323-324. doi: 10.1038/ 24521

Song, L., Guo, C., Li, T., and Zhang, S. (2017). $\mathrm{C}_{60} /$ graphene/g- $\mathrm{C}_{3} \mathrm{~N}_{4}$ composite photocatalyst and mutually- reinforcing synergy to improve hydrogen production in splitting water under visible light radiation. Ceram. Int. 43, 7901-7907. doi: 10.1016/j.ceramint.2017.03.115

Sudhaik, A., Raizada, P., Shandilya, P., Jeong, D.-Y., Lim, J.-H., and Singh, P. (2018). Review on fabrication of graphitic carbon nitride based efficient nanocomposites for photodegradation of aqueous phase organic pollutants. $J$. Ind. Eng. Chem. 67, 28-51. doi: 10.1016/j.jiec.2018.07.007
Sun, Z., Guo, J., Zhu, S., Mao, L., Ma, J., and Zhang, D. (2014). A highperformance $\mathrm{Bi}_{2} \mathrm{WO}_{6}$-graphene photocatalyst for visible light-induced $\mathrm{H}_{2}$ and $\mathrm{O}_{2}$ generation. Nanoscale 6, 2186-2193. doi: 10.1039/C3NR05249D

Tahir, M. (2019). La-modified $\mathrm{TiO}_{2} /$ carbon nanotubes assembly nanocomposite for efficient photocatalytic hydrogen evolution from glycerol-water mixture. Int. J. Hydrogen Energ. 44, 3711-3725. doi: 10.1016/j.ijhydene.2018. 12.095

Tong, H., Ouyang, S., Bi, Y., Umezawa, N., Oshikiri, M., and Ye, J. (2012). Nanophotocatalytic materials: possibilities and challenges. Adv. Mater. 24, 229-251. doi: 10.1002/adma.201102752

Wang, G., Zhang, W., Li, J., Dong, X., and Zhang, X. (2019). Carbon quantum dots decorated $\mathrm{BiVO}_{4}$ quantum tube with enhanced photocatalytic performance for efficient degradation of organic pollutants under visible and near-infrared light. J. Mater. Sci. 54, 6488-6499. doi: 10.1007/s10853-019-03316-y

Wang, J., Ng, Y. H., Lim, Y.-F., and Ho, G. W. (2014). Vegetable-extracted carbon dots and their nanocomposites for enhanced photocatalytic $\mathrm{H}_{2}$ production. RSC Adv. 4, 44117-44123. doi: 10.1039/C4RA07290A

Wang, J., Wang, G., Wang, X., Wu, Y., Su, Y., and Tang, H. (2019). 3D/2D direct Z-scheme heterojunctions of hierarchical $\mathrm{TiO}_{2}$ microflowers $/ \mathrm{g}-\mathrm{C}_{3} \mathrm{~N}_{4}$ nanosheets with enhanced charge carrier separation for photocatalytic $\mathrm{H}_{2}$ evolution. Carbon 149, 618-626. doi: 10.1016/j.carbon.2019.04.088

Wang, J., Wang, G., Wei, X., Liu, G., and Li, J. (2018). ZnO nanoparticles implanted in $\mathrm{TiO}_{2}$ macrochannels as an effective direct Z-scheme heterojunction photocatalyst for degradation of RhB. Appl. Surf. Sci. 456, 666-675. doi: 10.1016/j.apsusc.2018.06.182

Wang, Y., Chen, J., Liu, L., Xi, X., Li, Y., Geng, Z., et al. (2019). Novel metal doped carbon quantum dots/CdS composites for efficient photocatalytic hydrogen evolution. Nanoscale 11, 1618-1625. doi: 10.1039/C8NR05807E

Xia, Y., Li, Q., Lv, K., Tang, D., and Li, M. (2017). Superiority of graphene over carbon analogs for enhanced photocatalytic $\mathrm{H}_{2}$-production activity of $\mathrm{ZnIn}_{2} \mathrm{~S}_{4}$. Appl. Catal. B: Environ. 206, 344-352. doi: 10.1016/j.apcatb.2017.01.060

Xiang, Q., Yu, J., and Jaroniec, M. (2011). Preparation and enhanced visible-light photocatalytic $\mathrm{H}_{2}$-production activity of graphene/ $\mathrm{C}_{3} \mathrm{~N}_{4}$ composites. J. Phys. Chem. C 115, 7355-7363. doi: 10.1021/jp200953k

Xin, Q., Shah, H., Nawaz, A., Xie, W., Akram, M. Z., Batool, A., et al. (2018). Antibacterial carbon-based nanomaterials. Adv. Mater. doi: 10.1002/adma.201804838. [Epub ahead of print].

Xu, X. Y., Ray, R., Gu, Y. L., Ploehn, H. J., Gearheart, L., Raker, K., et al. (2004). Electrophoretic analysis and purification of fluorescent singlewalled carbon nanotube fragments. J. Am. Chem. Soc. 126, 12736-12737. doi: $10.1021 / \mathrm{ja} 040082 \mathrm{~h}$

Yang, M.-Q., Zhang, N., Pagliaro, M., and Xu, Y.-J. (2014). Artificial photosynthesis over graphene-semiconductor composites. Are we getting better? Chem. Soc. Rev. 43, 8240-8254. doi: 10.1039/C4CS00213J

Ye, A., Fan, W., Zhang, Q., Deng, W., and Wang, Y. (2012). CdS-graphene and CdS-CNT nanocomposites as visible-light photocatalysts for hydrogen evolution and organic dye degradation. Catal. Sci. Tech. 2, 969-978. doi: 10.1039/c2cy20027a

Ye, L., Fu, J., Xu, Z., Yuan, R., and Li, Z. (2014). Facile one-pot solvothermal method to synthesize sheet-on-sheet reduced graphene oxide (RGO) $/ \mathrm{ZnIn}_{2} \mathrm{~S}_{4}$ nanocomposites with superior photocatalytic performance. ACS Appl. Mater. Interfaces 6, 3483-3490. doi: 10.1021/am5004415

Yi, H., Huang, D., Qin, L., Zeng, G., Lai, C., Cheng, M., et al. (2018). Selective prepared carbon nanomaterials for advanced photocatalytic application in environmental pollutant treatment and hydrogen production. Appl. Catal. B Environ. 239, 408-424. doi: 10.1016/j.apcatb.2018. 07.068

Yu, H., Xiao, P., Tian, J., Wang, F., and Yu, J. (2016). Phenylamine-functionalized $\mathrm{rGO} / \mathrm{TiO}_{2}$ photocatalysts: spatially separated adsorption sites and tunable photocatalytic selectivity. ACS Appl. Mater. Interfaces 8, 29470-29477. doi: 10.1021/acsami.6b09903

Yu, H., Zhao, Y., Zhou, C., Shang, L., Peng, Y., Cao, Y., et al. (2014). Carbon quantum dots $/ \mathrm{TiO}_{2}$ composites for efficient photocatalytic hydrogen evolution. J. Mater. Chem. A 2, 3344-3351. doi: 10.1039/c3ta14108j

$\mathrm{Yu}, \mathrm{W}$., Xu, D., and Peng, T. (2015). Enhanced photocatalytic activity of g- $\mathrm{C}_{3} \mathrm{~N}_{4}$ for selective $\mathrm{CO}_{2}$ reduction to $\mathrm{CH}_{3} \mathrm{OH}$ via facile coupling of ZnO: a direct Z-scheme mechanism. J. Mater. Chem. A 3, 19936-19947. doi: 10.1039/C5TA05503B 
Zhang, Q., Sun, X., Ruan, H., Yin, K., and Li, H. (2017). Production of yellowemitting carbon quantum dots from fullerene carbon soot. Sci. China Mater. 60, 141-150. doi: 10.1007/s40843-016-5160-9

Zhang, S., Gu, P., Ma, R., Luo, C., Wen, T., Zhao, G., et al. (2019). Recent developments in fabrication and structure regulation of visible-light-driven g$\mathrm{C}_{3} \mathrm{~N}_{4}$-based photocatalysts towards water purification: a critical review. Catal. Today 335, 65-77. doi: 10.1016/j.cattod.2018.09.013

Zhang, X.-Y., Li, H.-P., Cui, X.-L., and Lin, Y. (2010). Graphene/TiO 2 nanocomposites: synthesis, characterization and application in hydrogen evolution from water photocatalytic splitting. J. Mater. Chem. 20, 2801-2806. doi: 10.1039/b917240h

Zhang, Y., Liu, Y., Gao, W., Chen, P., Cui, H., Fan, Y., et al. (2019). $\mathrm{MoS}_{2}$ nanosheets assembled on three-way nitrogen-doped carbon tubes for photocatalytic water splitting. Front. Chem. 7:325. doi: 10.3389/fchem.2019.00325

Zheng, L.-P., Zhu, Z.-Y., Li, Y., Zhu, D.-Z., and Xia, H.-H. (2008). Isotopic mass effects for low-energy ion channeling in single-wall carbon nanotubes. J. Phys. Chem. C 112, 15204-15206. doi: 10.1021/jp80 36999
Zhou, M., Dong, G., Yu, F., and Huang, Y. (2019). The deep oxidation of $\mathrm{NO}$ was realized by $\mathrm{Sr}$ multi-site doped $\mathrm{g}-\mathrm{C}_{3} \mathrm{~N}_{4}$ via photocatalytic method. Appl. Catal. B Environ. 256:117825. doi: 10.1016/j.apcatb.2019.1 17825

Conflict of Interest: The authors declare that the research was conducted in the absence of any commercial or financial relationships that could be construed as a potential conflict of interest.

The reviewer DG declared a shared affiliation, with no collaboration, with the authors NS, JH, YF, XW, LC, to the handling editor at time of review.

Copyright (C) 2019 Syed, Huang, Feng, Wang and Cao. This is an open-access article distributed under the terms of the Creative Commons Attribution License (CC BY). The use, distribution or reproduction in other forums is permitted, provided the original author(s) and the copyright owner(s) are credited and that the original publication in this journal is cited, in accordance with accepted academic practice. No use, distribution or reproduction is permitted which does not comply with these terms. 